\title{
Wage divergence and asymmetries in unemployment in a model with biased technical change
}

\author{
Citation for published version (APA):
}

Muysken, J., van Zon, A. H., \& Sanders, M. (1998). Wage divergence and asymmetries in unemployment in a model with biased technical change. MERIT, Maastricht Economic Research Institute on Innovation and Technology. MERIT Research Memoranda No. 023 https://doi.org/10.26481/umamer.1998023

Document status and date:

Published: 01/01/1998

DOI:

10.26481/umamer.1998023

Document Version:

Publisher's PDF, also known as Version of record

\section{Please check the document version of this publication:}

- A submitted manuscript is the version of the article upon submission and before peer-review. There can be important differences between the submitted version and the official published version of record.

People interested in the research are advised to contact the author for the final version of the publication, or visit the DOI to the publisher's website.

- The final author version and the galley proof are versions of the publication after peer review.

- The final published version features the final layout of the paper including the volume, issue and page numbers.

Link to publication

\footnotetext{
General rights rights.

- You may freely distribute the URL identifying the publication in the public portal. please follow below link for the End User Agreement:

www.umlib.nl/taverne-license

Take down policy

If you believe that this document breaches copyright please contact us at:

repository@maastrichtuniversity.nl

providing details and we will investigate your claim.
}

Copyright and moral rights for the publications made accessible in the public portal are retained by the authors and/or other copyright owners and it is a condition of accessing publications that users recognise and abide by the legal requirements associated with these

- Users may download and print one copy of any publication from the public portal for the purpose of private study or research.

- You may not further distribute the material or use it for any profit-making activity or commercial gain

If the publication is distributed under the terms of Article $25 \mathrm{fa}$ of the Dutch Copyright Act, indicated by the "Taverne" license above, 


\title{
Wage Divergence and Asymmetries in Unemployment in a Model with Biased Technical Change
}

\author{
J. Muysken, M. Sanders* and A. Van Zon \\ Department of Economics and MERIT \\ University of Maastricht
}

\begin{abstract}
In this article we assume two levels of skills and two classes of goods, one produced with a technology requiring high skills, the other produced with a technology that can be operated by both low and high skilled workers. Our model generates two distinct labour market regimes. In one regime we show technical change can be the cause of wage divergence between skilled and unskilled workers. This result is consistent with recent evidence on wage differentials. Adding the Phillips-effect shows this wage divergence can be "traded off" against unemployment of low skilled workers, and hence explains evidence on skill asymmetries in unemployment. Under the alternative regime these effects do not exist but high skilled workers may replace low skilled workers driving them out of their jobs.
\end{abstract}

Keywords

Skill biased technological change, job competition, wage divergence, low skilled unemployment.

* Corresponding author

P.O. Box 616

6200 MD Maastricht, The Netherlands

e-mail: m.sanders@algec.unimaas.nl

phone number: +31433883691 


\section{Introduction}

Over the past decade or so, the labour market perspectives for low skilled workers have worsened dramatically throughout the OECD. This problem has been widely recognised and most authors agree that the causes for this deterioration of labour market perspectives are to be found in the changing composition of labour demand. The OECD formulated the problem as:

\section{.... one of the most serious current challenges in the OECD area is the trend shift in the composition of the demand for labour away from unskilled and towards skilled labour. (OECD (1994))}

Throughout the OECD, however, it is interesting to note the different manifestations of this seemingly common shift in demand.

Unemployment is high and rising relatively for low-skilled workers in Europe (OECD (1994), Draper and Manders (1997)) as is the duration of their average unemployment spell (Muysken en Ter Weel (1998)). At the same time we find skilled workers in jobs that do not require their level of skill, the so called trickling down effect (CBS (1996)).

In the US and other Anglo-Saxon countries, on the contrary, overall unemployment is at an all time low. Low skilled workers still suffer a much higher unemployment rate relative to their high skilled competitors (OECD (1994)). The most dramatic manifestation of the shifting demand, however, is through relative wages. In these countries they show a very strong tendency to diverge. A result that is almost absent in mainland Europe (OECD (1994)).

For understanding these developments two questions have to be addressed. First of all one has to explain what may have caused the demand for low skilled labour to drop so sharply over the eighties throughout the developed world. Then one can address the issue of the widely different responses to this seemingly common cause.

In this paper we will address these issues by presenting a model that shows how biased technical change might cause the relative demand for low skilled workers to drop, but also allows for two distinct labour market outcomes in response to this drop in relative demand. We show that the drop in demand can cause either strong wage divergence that can partially be traded off against asymmetric unemployment. Or it causes a trickling down effect of high skilled workers pushing low skilled workers out of their jobs, but relative wages remain stable.

\section{Theoretical Background}

Two possible reasons for the drop in the demand for low skilled workers have been distinguished in the literature. On the one hand there are those that link the shift in demand to the process of globalization and increasing trade with low wage/low skilled countries. Key references are Leamer (1994,1995), Burtless (1994) and Lawrence and Slaughter (1993). On the other hand there are those that link this demand shift to pervasive changes in production technology often linked to the IT-revolution. Some notable references are Krugman (1995), Jackman (1995), Howell (1995) and Agenor and Aizenman (1996). The issue remains to be resolved both in theoretical and empirical work on either approach.

Both approaches, however, can be traced back in the classical economic literature. The trade hypothesis follows from extensions and elaborations on the standard factor price equalization theorem formulated by Stolper-Samuelson. The idea of job destruction by 
technical change can be traced back all the way to Ricardo's Principles and Marx' Capital and the ideas of technical bias have been formalised in Hicks' Theory of Wages. ${ }^{1}$ The debate on the issue has never really conquered the lime light in economics but notable authors such as Binswanger (1974a, 1974b), Kennedy (1964), Phelps (1966) and Salter (1960) have contributed to a sizeable literature on the issue.

From the research available so far we cannot safely disregard either hypothesis and both will probably explain current events in the OECD partially. However in this paper we concentrate on linking technological change to labour demand in a way that allows us to show a possible source of bias in technical change that may cause the shift in demand. The reason for our choice of focus is twofold.

First we simply find the idea of biases in technical change intuitively appealing. It seems evident from casual observation that different forms of technical change involve a particular change in the organisation of the productive process. Introducing a new product usually requires the set up of a whole new production line, which requires a skilled labour force that is capable of dealing with the unforseen problems that occur during this phase of introduction and commercialisation of the new product. As the product matures, the firm can develop and introduce an interface that allows less skilled persons to perform the routine elements in the production process and makes the skilled workers more productive.

Secondly the OECD (1994) presents evidence that the importance of trade in explaining the changes in employment are but a fraction of the impact of productivity changes throughout the OECD, which could be interpreted as evidence that technical change has a more profound impact on labour demand in general. Furthermore the relative size of intra OECD trade to trade with non-OECD countries seems to rule out a severe impact of wage competition from low wage countries at the aggregate level.

A final indication for the relative importance of the technical bias hypothesis comes from Feenstra and Hanson (1997) who show there is also evidence of wage divergence in developing countries. Although circumstantial this evidence supports our intuition and justifies our choice of focus.

On the issue of different responses, notably between mainland Europe and the US, a booming literature has developed over the last few years. Many authors have, and justly so, looked at the differences in wage formation and labour market institutions for an explanation (Teulings and Hartog (1998)) and indeed found that many of the differences in labour market performance can be explained.

Krugman (1994) was the first to address the issue and in his paper he argues Europe's labour market rigidities imply an adjustment to the shifting demand in unemployment, whereas the flexible labour markets in the US translate this drop in demand into a decline in relative (and even absolute) wages: "Moneyless America, Jobless Europe". Appealing as this story seems, however, it does not explain the facts.

Nickell and Bell (1995) have shown European high unemployment is not explained by a drop in low skilled labour demand. Furthermore data from the OECD (1994) show high absolute unemployment rates but these are not as skill biased as those in the United States as Krugman's analysis would predict. In this paper we therefore set out to develop a model that provides an alternative and perhaps complementary explanation for the observed differences in labour market responses.

Back in those days the distinction between skilled and unskilled labour was not made of course, but the idea of biases against one of the production factors remain valid even today. 


\section{Outline}

The challenge is now to build a model in such a way that technical change can cause both wage divergence and low skilled unemployment or wage stability and the trickling down of skills. In this article we assume two levels of skill ${ }^{2}$ and two classes of goods, one produced with a highly sophisticated technology requiring high skills, the other produced with a relatively simple technology that can be operated by both low and high skilled workers. Thus an asymmetry in employment opportunities is assumed.

Technical change can be introduced in the model by allowing the number of either class of goods to increase over time. The development of new products, labelled product innovation, causes the number of goods produced on high sophisticated technologies to increase. The assumption is that producing a new good requires higher flexibility, higher problem solving capabilities and more creativity: in short, higher skills on behalf of the worker.

An expansion of the range of goods that can be produced with low skilled labour is labelled process innovation. One could think of technical change as an improvement in the interface between production technology and the worker, thus allowing a low skilled worker to perform complicated tasks, previously only manageable by high skilled workers. Not only does the interface allow low skilled workers to become productive, it also allows the high skilled workers to be more productive than before. New goods thus mature as their interface develops over time. ${ }^{3}$

Using this framework we show that technical change can be the prime cause of wages diverging between skilled and unskilled workers under a particular labour market regime. A result consistent with the empirical evidence on wage differentials in the Anglo-Saxon world. Adding Phillips-effects to the model shows wage divergence can be "traded off" against increasing relative unemployment of low skilled workers under this regime. This result could explain the empirical evidence on skill asymmetries in unemployment. The model, however, also yields a second regime in which wages do not diverge but high skilled people occupy jobs in the low skilled sector, consistent with the evidence on employment and wage patterns on mainland Europe. We show that under this regime a chimney effect will occur as long as skill mismatch exists. That is, as long as high skilled workers are employed on low skilled jobs, increasing high skilled jobs may alleviate low skilled unemployment.

The basic model with a competitive labour market is presented in section 2 . The model is extended to include unemployment in section 3, whereas in section 4 technological change is introduced and a comparative statics analysis is presented. Finally, some concluding remarks are made in section 5 .

2 In a later stage we hope to refine the model to deal with more skill levels or a continuum of skills. This will hopefully increase the plausibility and intuitive appeal of our model.

This setup is reminiscent of Krugman's (1979) model of North-South Trade. 


\section{The Basic Model}

\section{General Settings}

Our simple economy consists of two types of households. We have consumers that consume a range of goods and derive utility thereof. The utility function was taken from Krugman (1979) and has the well known "love of variety" characteristics. All consumers are assumed identical and are represented by an individual that maximises his and therefore total utility by choosing the appropriate levels of consumption for each good, subject to his budget constraint.

The variety of goods is produced by a range of production units that can only be distinguished on the basis of their technology determined input requirements. Some varieties can only be produced by high skilled labour due to the sophistication of the production process. Others are manufactured in a routine like manner and can thus be produced by employing either high or low skilled workers. There are no other inputs in our model. Both consumers and producers can only distinguish between high- and low-tech goods. Within a class of goods, however, the goods are perfectly symmetric both in terms of utility and production technology.

By assuming price taking behaviour on behalf of the consumer and monopolistic price setting by producers we find all high-tech goods command the same price, as do all low-tech goods, within their class.

The producers set prices given demand, wages and their production technology. By the symmetry and diminishing returns assumed within classes their decision is reduced to choosing an average output level for high and low-tech goods, where output per variety within a class is the same. ${ }^{4}$ In the following subsections we first analyse the consumer decision and the producers' decisions in isolation. Then the goods market equilibrium can be derived. By confronting the labour demand that is derived from profit maximization with exogenous and endogenous labour supply respectively we can close the model and analyse the impact of technical change in comparative statics.

\section{The Consumer Decision}

Consumers maximize their utility. Assume a representative consumer whose utility is given by:

$$
U=\left[\sum_{i=1}^{n} c_{i}^{\alpha}\right]^{1 / \alpha} \quad 0<\alpha<1
$$

where $c_{i}$ is the consumption of good $i$ and $n$ is the number of varieties of goods produced and $1 / 1+\alpha$ the elasticity of substitution between two varieties. When we distinguish between a class of goods that can be produced using high skilled labour and one in which both types of labour can be used, we may write this utility function also as:

$$
U=\left[n_{H} c_{H}^{\alpha}+n_{L} c_{L}^{\alpha}\right]^{1 / \alpha}
$$

$4 \quad$ Here we deviate from Krugman (1979) who assumes a one-on-one technology. 
where subscripts $H(\mathrm{igh})$ and $L(\mathrm{ow})$ indicate the level of sophistication of the technology used to produce those goods and $c_{H}$ and $c_{L}$ are the average amounts of consumption of high and low sophisticated goods, respectively. ${ }^{5}$ Finally $n_{H}$ and $n_{L}$ indicate the number of varieties of both goods. We maximise the utility function subject to the simple (Walrasian) budget constraint, $Y=P_{H} n_{H} c_{H}+P_{L} n_{L} c_{L}$, where $Y$ is income and $P_{H}$ and $P_{L}$ are the price levels for both classes of goods. Then relative average consumption of high and low-tech goods is a function of the relative price:

$$
\frac{c_{H}}{c_{L}}=\left[\frac{P_{H}}{P_{L}}\right]^{\frac{1}{\alpha-1}}
$$

\section{The Producers and Goods Market Equilibrium}

Each variety is produced in a situation of profit maximisation under imperfect competition on the product markets (varieties are heterogenous by assumption) and perfect competition on the labour market. Labour (measured in efficiency units) is the only factor of production distinguished in the model.

We identify two groups of producers. As was mentioned above, the output of a variety of high sophisticated goods can only be produced by employing high skilled labour. High skilled labour not employed by the high tech producers is available for the production of low sophisticated goods as is the entire supply of low skilled labour. The output of any variety exhibits diminishing returns in the relevant input. Due to the symmetry in production within a class of products and the diminishing returns, the average output per variety is equal to the output of any variety within that class. It can be written as a function of the labour input per variety. Average output of a low sophisticated variety is given by:

$$
x_{L}=\left[l_{L}^{e}\right]^{\beta} \quad 0<\beta<1
$$

Where $l_{L}^{e}=\left(L_{L}+\epsilon L_{H L}\right) / n_{L}$, is the labour input on all $n_{L}$ low sophisticated varieties measured in efficiency units. $L_{L}$ is the number of low skilled workers employed and $L_{H L}$ is the number of high skilled workers on low sophisticated jobs. The latter workers are assumed to be $\epsilon$ times as efficient as low skilled workers. ${ }^{6}$ Equivalently for all $n_{H}$ high sophisticated varieties output is equal to average output:

$$
x_{H}=\left[l_{H H}\right]^{\beta} \quad 0<\beta<1
$$

Where $l_{H H}=L_{H H} / n_{H}$ is the amount of high skilled labour employed in the production of each

5 In a symmetric utility function consumers optimize by spreading consumption equally across all varieties that command the same price. Hence consumers consume the average amount of all varieties within each class and $\mathrm{c}_{\mathrm{H}}=\left(\mathrm{c}_{\mathrm{h} 1}+\mathrm{c}_{\mathrm{h} 2}+\ldots+\mathrm{c}_{\mathrm{hnH}}\right) / \mathrm{n}_{\mathrm{H}}$.

$6 \quad \epsilon>1$. Some tentative evidence in Van Zon, Muysken and Meijers (1998) has shown this value is approximately 1.25 in the Netherlands between high and medium and medium and low level skills. 
high tech variety. Profits for both types of producers are given by:

$$
\begin{gathered}
\pi_{H}=P_{H} x_{H}-w_{H} l_{H H} \\
\pi_{L}=P_{L} x_{L}-w_{L} l^{e}{ }_{L}
\end{gathered}
$$

Where $w_{H}$ and $w_{L}$ are the wages paid to one efficiency unit of high and low skilled labour respectively. Producers now set prices to maximise profits given the relative demand for their product (3), the production function (4) and (5) and wages. Standard optimization yields the profit maximizing relative average supply as a function of relative prices and wages:

$$
\frac{x_{H}}{x_{L}}=\left[\frac{w_{H} / P_{H}}{w_{L} / P_{L}}\right] \frac{\beta}{\beta-1}
$$

Equating relative average supply (8) and demand (3) yields the relative prices as a function of relative wages for which the goods markets clear:

$$
\frac{P_{H}}{P_{L}}=\left[\frac{w_{H}}{w_{L}}\right] \frac{\beta-\alpha \beta}{1-\alpha \beta}
$$

Equation (9) describes the relative wage-price frontier for which the goods market is in equilibrium. Figure 1 shows this frontier, labeled $G M E$, is a concave line through the origin in $P, w$-space, where $P$ and $w$ are the relative price and wage ratio respectively.

\section{The Demand for Labour}

A similar approach can be followed to derive the relative wage-price frontier for the labour market. Since labour is the only factor of production in the model, it follows that the supply of a certain type of good directly generates a corresponding demand for the appropriate type of labour.

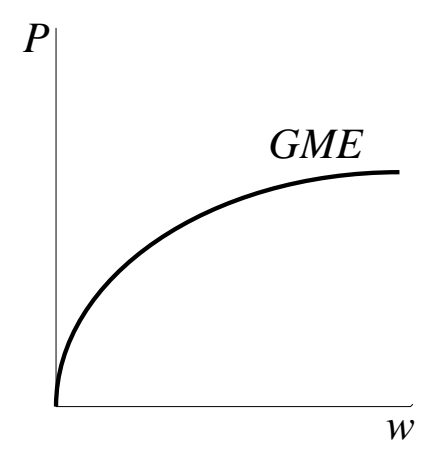

Figure 1: Goods Market Equilibrium 
By substituting for output in (8) by (4) and (5), we can solve for the relative implied demand for labour (in appropriately skilled efficiency units) as a function of the relative product wages:

$$
\frac{l_{H}^{D}}{l_{L^{e}}^{D}}=\left[\frac{w_{H} / P_{H}}{w_{L} / P_{L}}\right]^{\frac{-1}{1-\beta}}
$$

Inelastic Labour Supply and Equilibrium in the Labour Market

We now first introduce exogenous labour supply to provide a benchmark case. When labour is supplied inelastic, relative supply in efficiency units can be written as:

$$
\frac{l^{S}{ }_{H H}}{l^{S}{ }_{L^{e}}}=\frac{\left(L^{*}{ }_{H}-L_{H L}\right) / n_{H}}{\left(L^{*}{ }_{L}+\epsilon L_{H L}\right) / n_{L}}
$$

Equating (10) and (11) yields the relative wage-price frontier for which the labour market is in equilibrium:

$$
\frac{P_{H}}{P_{L}}=\frac{w_{H}}{w_{L}}\left[\frac{\left(L^{*}{ }_{H}-L_{H L}\right) / n_{H}}{\left(L^{*}{ }_{L}+\epsilon L_{H L}\right) / n_{L}}\right]^{1-\beta}
$$

It can be verified in equation (12) that producers will set relative prices proportional to relative wages with a factor of proportion that depends on the relative availability of high skilled workers and the relative size of the high skilled sector. Equation (12) can be represented in $w, P$-space as well. It traces out a linear upward sloping line on which the labour market is in equilibrium. The slope of the curve is, however, conditional upon the value for $L_{H L}$ and decreases as $L_{H L}$ increases. Figure 2 shows the Labour Market Equilibrium, $L M E$, conditional on $L_{H L}=0$.

Figure 2: Equilibrium in the Labour Market

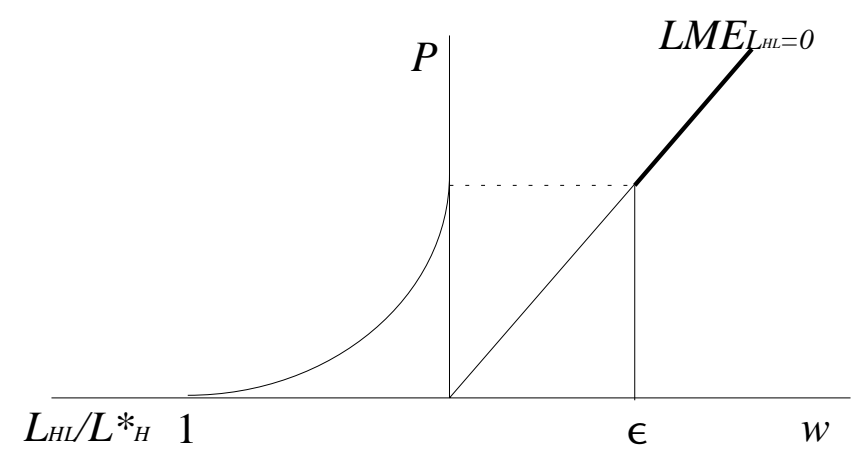

As we have mentioned above, $L_{H L}$ refers to the demand for high-skilled workers on low skilled jobs. It can be shown from the first order conditions for low skilled producers that these workers will only be employed on these jobs when relative wages match relative efficiency, 
that is $L_{H L}>0$ can only occur when $w_{H} / w_{L} \leq \epsilon$. It is profitable to replace low skilled workers with high skilled workers on low skilled jobs as long as the latter condition is a strict inequality. On the other hand, high skilled wages should always exceed those for low skilled jobs, that is $w_{H} \leq \epsilon . w_{L}$. Otherwise all high-skilled workers will seek employment on low skilled jobs. Therefore an equilibrium with $0<L_{H L}<L_{H}^{*}$ is only possible for $w_{H} / w_{L}=\epsilon$.

For the relative wage equal to $\epsilon$, equation (12) can be solved to yield skill mismatch, $L_{H L} / L_{H}^{*}$, as a function of relative prices only:

$$
\frac{L_{H L}}{L^{*}{ }_{H}}=\frac{\frac{L^{*}{ }_{H} / n_{H}}{L^{*}{ }_{L} n_{L}}-\left[\frac{P_{H}}{P_{L}}\right] \frac{1}{1-\beta} \epsilon^{\frac{1}{\beta-1}}}{\epsilon^{\frac{\beta}{\beta-1}\left[\frac{P_{H}}{P_{L}}\right] \frac{1}{1-\beta}+\frac{L^{*}{ }_{H} / n_{H}}{L^{*}{ }_{L} / n_{L}}}}
$$

The left quadrant in Figure 2 shows this relationship as a downward sloping curve with a positive intercept at the relative price level where the $L M E_{H L=0}$-curve intersects $w_{H} / w_{L}=\epsilon$.

The reasoning above implies that for higher relative wages, i.e. $w>\epsilon$, no high skilled labour will be employed on low-skilled jobs. Therefore the LME line with $L_{H L}=0$ will be only relevant for $w>\epsilon$, as is indicated by the thick line in Figure 2, from point A upwards.

\section{The Equilibrium with Inelastic Labour Supply}

In order to determine the simultaneous equilibrium of our model Figure 3 combines the goods and labour market equilibrium wage-price frontiers. As the $G M E$ is a concave line in $w, P$ space and the $L M E_{L H L=0}$ is upward sloping and linear, we know there is a unique point of intersection. From (11) we know this point of intersection moves to the right as the number of high skilled workers in the low skilled sector increases, since this would rotate the $L M E$ curve clockwise. This implies there are two possible equilibria in the model.

Figure 3 shows the straightforward case where the $G M E$-curve intersects the $L M E$-curve

Figure 3: The Complete Specialisation Equilibrium

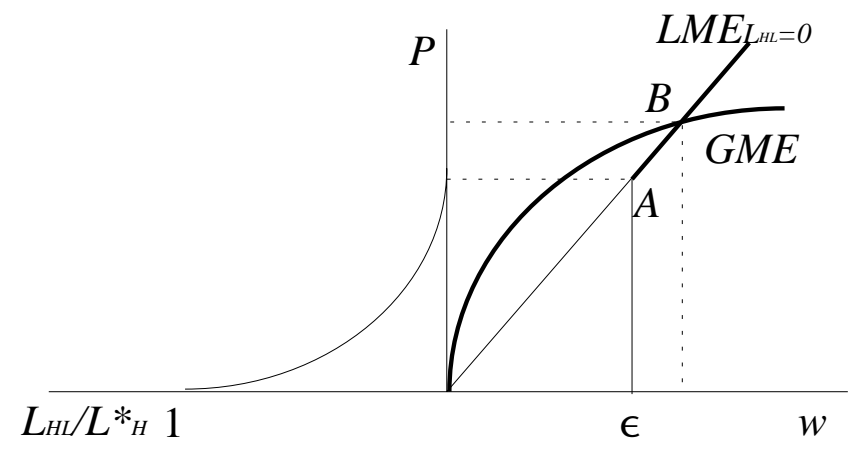

above point $A$, the point of intersection of the $G M E$-curve and the line $w=\epsilon$. In such an equilibrium the wages paid in the high skilled sector are too high for low tech producers to benefit from their employment. This implies they will set $L_{H L}=0$ and relative wages now adjust to bring about equilibrium. The economy would remain in a point such as $B$ and the left quadrant shows the employment rate of high skilled workers in the low tech sector is 0 . Hence 
we label this equilibrium complete specialisation.

Another possible equilibrium is illustrated in Figure 4 and prevails when the $G M E$-curve intersects with the $L M E_{L H L=0}$-curve below point $A$. In such an equilibrium low tech producers find it attractive to employ high skilled workers. In the process of competing for high skilled workers they will drive up the relative wages until $w=\epsilon$. This will rotate the $L M E$-curve to

Figure 4: The Incomplete Specialisation Equilibrium

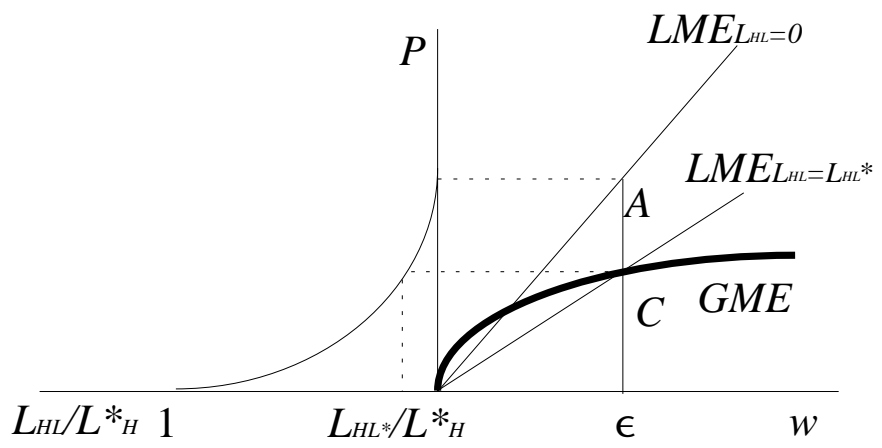

$L M E_{L H L=L H L^{*}}$ The economy reaches an equilibrium at point $C$, where the $G M E$-curve intersects with $w=\epsilon$. In such an equilibrium $L_{H L} / L^{*}{ }_{H}>0$ (left panel) and there is positive skill mismatch $L_{H L^{*}}$ We label this equilibrium incomplete specialisation.

As can be seen from equations (9) and (12), the $G M E$-curve does not change when labour supply or the number of varieties change, whereas the $L M E$-curve does. That is, the $L M E$ curve moves clockwise both when $L_{H} * / L_{L} *$ and $n_{L} / n_{H}$ increase. This implies that when low skilled labour is abundant, the ratio of high wages relative to low wages will be high and no high skilled labour will be employed on low skilled jobs. As one might expect, this tendency will be reinforced by product innovations that increase $n_{H}$. For such innovations increase the relative scarcity of high skilled labour. We will discuss the impact of technical change more in detail in section 4 .

\section{Wage Formation and Unemployment}

So far we have not allowed labour supply to respond to these wage adjustments and have assumed zero unemployment, so unemployment rates can obviously not be compared. This issue will be addressed in the next sections by assuming endogenous labour supply and repeating the analysis outlined above.

\section{Wage Formation and Labour Market Equilibrium with Elastic Labour Supply}

When we endogenise labour supply and allow for unemployment the results will obviously change, although not qualitatively. We will, for the purpose of this paper, abstract from microeconomic foundations underlying our labour supply conditions. For now we refer to f.e. Layard, Nickell and Jackman (1994) and put the exact derivation of our assumptions on the agenda for further research. Moreover, in the Annex to this paper we present an alternative process of wage formation which leads to results similar to the present analysis.

Here we assume a process of wage bargaining, both by high-skilled workers and by lowskilled workers, taking each other's wage as a reference, in the context of a right-to-manage 
model. ${ }^{7}$ High skilled workers will negotiate a wage, $w_{H}$, for the high skilled sector taking demand for high skilled employment in that sector, $L_{H H}$, into account and using as an outside option, the wage a high skilled worker can earn in the low skilled sector, $\epsilon w_{L}=w_{H L}$. The excess high skilled labour supply, which we assume to be the difference between exogenous total high skilled labour supply, $L_{H}{ }^{*}$, and the level of employment in the high skilled sector, will turn to the low skilled sector, where the low skilled wage is determined in a bargaining process by low-skilled workers.

The high skilled wages bargained in the high skilled sector are given by:

$$
w_{H}=\gamma w_{H L}\left[\frac{1-u_{H H}}{1-u^{*}}\right]^{\psi} \quad 0<\psi<1 \quad \gamma>1
$$

where $u_{H H}=\left(L_{H}{ }^{*}-L_{H H}\right) / L_{H} *$ is the mismatch and unemployment rate of high skilled workers and $u^{*}$ is the exogenous rate that high-skilled workers accept when their demands are met. ${ }^{8}$ The wage claim is a positive function of the level of employment of high skilled workers on high skilled jobs, expressing their willingness to accept lower wages when mismatch is reduced. Furthermore high skilled workers are assumed to take a fixed mark up, $\gamma$, over their outside option as a base wage.

Low skilled workers are assumed to take the productivity adjusted high skilled wage, $w_{H} / \epsilon$, as their ultimate target and will bargain for a fraction, $1 / \gamma$, of that target. The bargained low skilled wage is obviously a positive function of the level of low skilled employment relative to the reference level. Hence we assume: ${ }^{9}$

$$
w_{L}=\frac{1}{\gamma} \frac{w_{H}}{\epsilon}\left[\frac{1-u_{L}}{1-u^{*}}\right]^{\psi}
$$

where $u_{L}=\left(L_{L} *-L_{L}\right) / L_{L} *$ is the low skilled unemployment rate and $u^{*}$ represents the exogenous reference unemployment rate that low skilled workers accept when their demands are met. This equation expresses the trade off between additional unemployment and higher relative wages low skilled workers are willing to make.

7 For simplicity we assume that unemployment benefits are equal to the wage that would have been earned when working, minus benefits from leisure. Therefore being unemployed is not a threat in the bargaining process.

8 Since we assume that in this wage bargaining process unemployment benefits do not pose any threat, high-skilled workers are indifferent between working on low skilled jobs or being unemployed.

$9 \quad$ Taking the parameters $u^{*}, \gamma$ and $\psi$ for both bargaining processes is just for convenience and does not alter the qualitative results. 
These equations can be rewritten to give the following labour supply equations:

$$
L^{s}{ }_{L}=\left[\frac{w_{H}}{\gamma \in w_{L}}\right]-\frac{1}{\psi}\left[1-u^{*} L^{*}{ }_{L}\right.
$$

and:

$$
L_{H H}^{s}=\left[\frac{w_{H}}{\gamma \in w_{L}}\right]^{\frac{1}{\psi}}\left[1-u^{*}\right]_{H}^{*}
$$

for low and high skilled labour respectively.

We assume high skilled workers are still allocated between the low and high tech sector, such that $L_{H L}^{s}=L_{H}^{*}-L_{H H}^{s}$ holds. Therefore we can write relative labour supply per variety in efficiency units as:

$$
\frac{l_{H H}^{S}}{l_{L^{e}}^{S}}=\frac{n_{L}}{n_{H}} \frac{\left.\left[\frac{1}{\gamma \in} \frac{w_{H}}{w_{L}}\right] \bar{\psi} \frac{1}{\gamma \in} \frac{w_{H}}{w_{L}}\right] \frac{1}{\psi}\left[1-u^{*}\right] L^{*}{ }_{H}}{\left[1-u^{*}\right] L^{*}{ }_{L}+\epsilon L_{H L}}
$$

This is the endogenous relative supply version of equation (11). Confronting this with total labour demand as in equation (10) we find the relation between relative prices and relative wages for which the labour market is in equilibrium. Again the resulting $L M E$-curve is conditional on the level of $L_{H L}$ :

$$
\frac{P_{H}}{P_{L}}=\frac{w_{H}}{w_{L}}\left[\frac{n_{L}}{n_{H}}\right]^{1-\beta}\left[\frac{\left[\frac{1}{\gamma \epsilon} \frac{w_{H}}{w_{L}}\right] \frac{1}{\psi}\left[1-u^{*}\right] L_{H}^{*}}{\left[\frac{1}{\gamma \epsilon} \frac{w_{H}}{w_{L}}\right]^{-\frac{1}{\psi}}\left[1-u^{*} L^{*}{ }_{L}+\epsilon L_{H L}\right.}\right]^{1-\beta}
$$

The analysis is less straightforward in this case since under our assumptions on the wage formation process the supply of high skilled labour on high skilled jobs is bound to a minimum level of employment at a relative wage of $\epsilon$. This implies that $L_{H L}$ is bound by a maximum under incomplete specialisation and an equilibrium is no longer guaranteed to exist. We assume, however, that this constraint does not become binding and the high skilled labour market can be induced to release labour into the low skilled jobs at the relative wage $\epsilon$ sufficiently to achieve equilibrium. In Figure 5 we have presented the $L M E$-curves conditional on $L_{H L}=0$ and $L_{H L}=L_{H L}{ }^{\max }$. It can be easily verified that both trace out an upward sloping convex curve through the origin. Hence there will be one unique point of intersection with the $G M E$-curve in the positive $w, P$-plane. In the upper left quadrant we again show skill mismatch 
Figure 5: Labour Market Equilibrium with Endogenous Supply

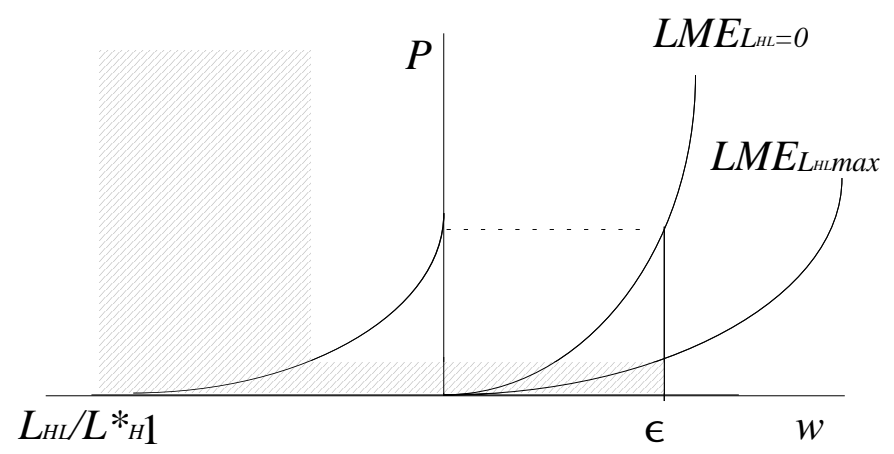

as a function of relative prices (by setting relative wages equal to $\epsilon$ in (19)). We can now turn to the equilibrium on both the goods market and the labour market.

\section{Equilibrium with Unemployment}

Again two equilibria are possible. In Figure 6 we have combined Figure 1 and Figure 5 to show these possible equilibria. When the intersection of $G M E$ and $L M E$ lies above $A$ again we end up in a complete specialisation equilibrium. As we know high skilled employment in the low skilled sector is zero under this regime, the rate $u_{H H}$ can be interpreted as the

Figure 6: Possible Equilibria with Endogenous Labour Supply

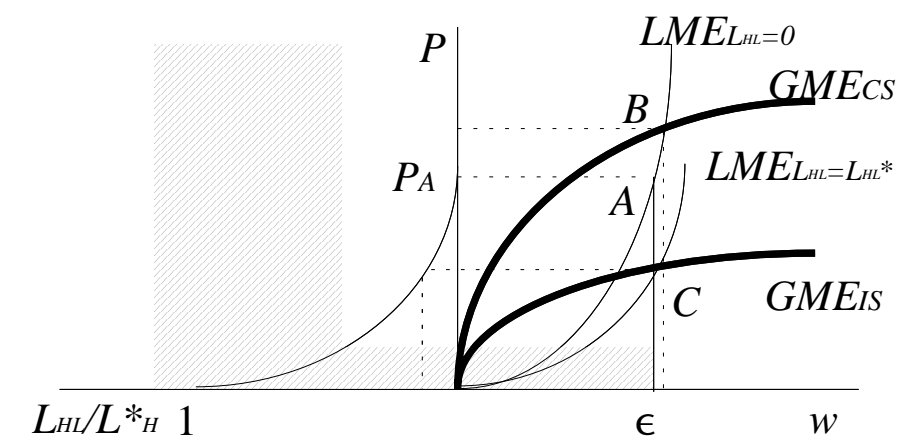

unemployment rate for high skilled workers, that can be calculated from (14). The equilibrium unemployment rate for low skilled workers follows in a similar fashion directly from (15). Figure 7 shows these unemployment rates as a function of the equilibrium relative wage. By assuming the same parameters in both wage equations we obtain the result that the curves intersect at $w=\gamma \epsilon$, i.e. beyond $w=\epsilon$. Furthermore we can establish that for large enough $w$ unemployment for high skilled workers is zero.

When the intersection of $L M E$ and $G M E$ lies below point $A$ in Figure 6 again low tech producers will hire high skilled workers, causing the $L M E$-curve to rotate clockwise until relative wages have increased up to $\epsilon$. Ultimately the economy is in equilibrium at point $C$. As before under this regime high skilled workers occupy low skilled jobs as can be seen in the upper left quadrant, and we have incomplete specialisation. To analyse the unemployment rates under this equilibrium we use equations (14) and (15) and the employment rate for high skilled on low skilled jobs. Low skilled unemployment follows directly from setting $w=\epsilon$ in (15) and is constant under this regime. The high skilled unemployment rate follows from 
subtracting the employed mismatch, obtained by setting $w=\epsilon$ in (19), from the supplied mismatch $u_{H H}$ under $w=\epsilon$. The latter is a constant and since the former is a decreasing function of relative prices - cf. the function $\mathrm{e}_{\mathrm{HH}}$ in Figure 8 - we can analyse the equilibrium unemployment rates in $P, u$-space. Figure 8 presents both unemployment rates under incomplete specialisation ${ }^{10}$. We do not consider the possibility that $u_{H}$ is negative (low skilled

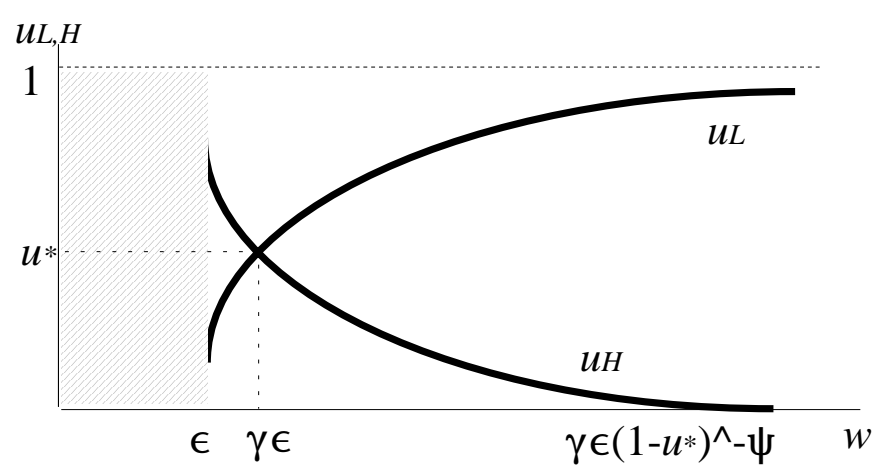

Figure 7: Unemployment for High and Low Skilled Labour under Complete Specialisation

producers cannot find high skilled workers to meet their demand) for this would only occur when the low tech product range is extremely large and the low skilled labour force is extremely small relative to the high skilled product range and labour force respectively.

In Figure 6 we show that compared to the incomplete specialisation equilibrium wages have diverged under complete specialisation. By the convexity of the $L M E$-curve, however, we also know that wages have not diverged as much as in the model with exogenous labour

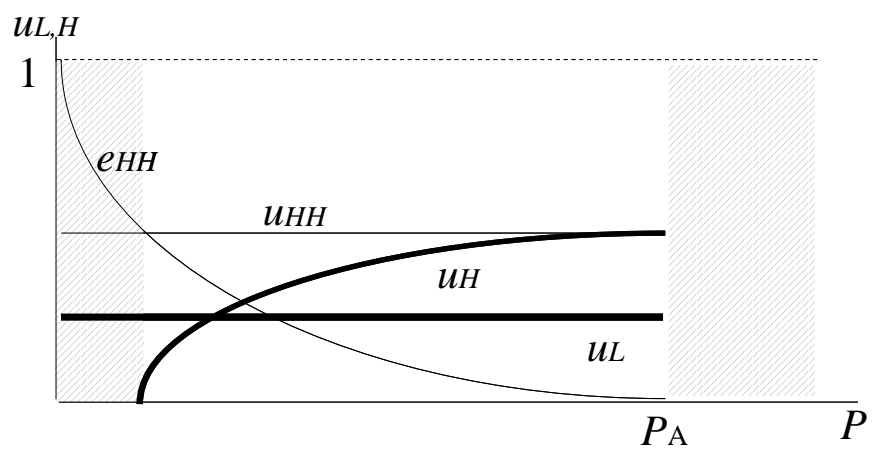

Figure 8: Unemployment for High and Low Skilled Labour under Incomplete Specialisation

supply. Relative unemployment rates might or might not have diverged between these regimes. Figure 7 shows unemployment rates move in favour of high skilled workers as wages diverge. Hence we may conclude unemployment rates can indeed be traded off against wage divergence under this regime. It depends on the parameters of the model where most of the adjustment to equilibrium arises. In the next section we will turn to the comparative statics of the model, when we allow for technical change.

The figure can be extended beyond $\mathrm{P}_{\mathrm{A}}$, then it will be analogous to Figure 7 . 


\section{Comparative Statics; Introducing Technical Change}

In this section we introduce technical change into the model to see how it may explain the empirical evidence referred to in the introduction. First we define technical change in our model as the expansion of either range of product varieties. Increasing the total range of varieties implies introducing new products into the economy, which we label product innovation.

These new products are both in terms of utility and production technology perfectly symmetric to the already existing products in the range $n_{H}$. By our assumption of love of variety, consumers will respond to the introduction of these new products by keeping their average consumption of all products in the $n_{H}$ range constant given the relative prices. However, these prices might change since the production of the additional new goods requires the allocation of high skilled labour to the new firms and hence high skilled wages will tend to increase. Since relative prices are a mark up over relative wages by equation (9) this causes relative prices to increase as well.

There may, however, be a reserve of high skilled labour in low skilled jobs. The high skilled labour will be attracted by the higher relative wage. This inflow can offset the upward pressure on wages in the high skilled sector and create an upward pressure in the low skilled labour market. Hence relative wages can remain stable when the movement of high skilled labour can offset the initial shock. Both high and low skilled wages rise proportionally under such an adjustment.

When such a reserve of mismatched labour is unavailable or insufficient to absorb the shock, high skilled wages will increase relative to low skilled wages and hence relative prices rise as well. This causes consumers to reduce their average consumption of high tech products and increase the average consumption of low tech products. As a consequence marginal productivity moves in favour of high skilled workers, which brings relative marginal productivity in line with the higher relative wages.

The other type of technical change we can distinguish is the development of processes and interfaces that allow low skilled workers to produce products that required high skills before. We label these process innovations. In our model this implies an increase in the range $n_{L}$ and a corresponding decrease in $n_{H}$. In our model this will cause exactly the opposite of the above. Consumers will keep the average consumption of products in the range $n_{L}$ constant given relative prices and hence the demand for low skilled efficiency units increases. When there exists a positive mismatch at the outset, relative wages are at $\epsilon$. Hence low tech producers can compete for additional high skilled labour in the high skilled labour market. This implies an outflow of high skilled labour from the high skilled sector that puts an upward pressure on high skilled wages as well. A new equilibrium is reached when enough high skilled labour has moved to low skilled jobs to produce the additional output. Wages again rise in proportion and hence relative wages remain stable (at $\epsilon$ ) as do relative prices. 
When there is no initial mismatch low skilled wages increase and relative wages decrease. This will cause relative prices to drop as well and consumers lower the average consumption of products in the $n_{L}$ range in response. When this relative wage change is sufficient to absorb the initial shock no mismatch will occur in the new equilibrium. However, one should note that relative wages cannot fall below $\epsilon$ without provoking the inflow of high skilled labour from the high skilled sector.

Figure 9 can be used to illustrate the analysis above. As can be verified in equation (19) an

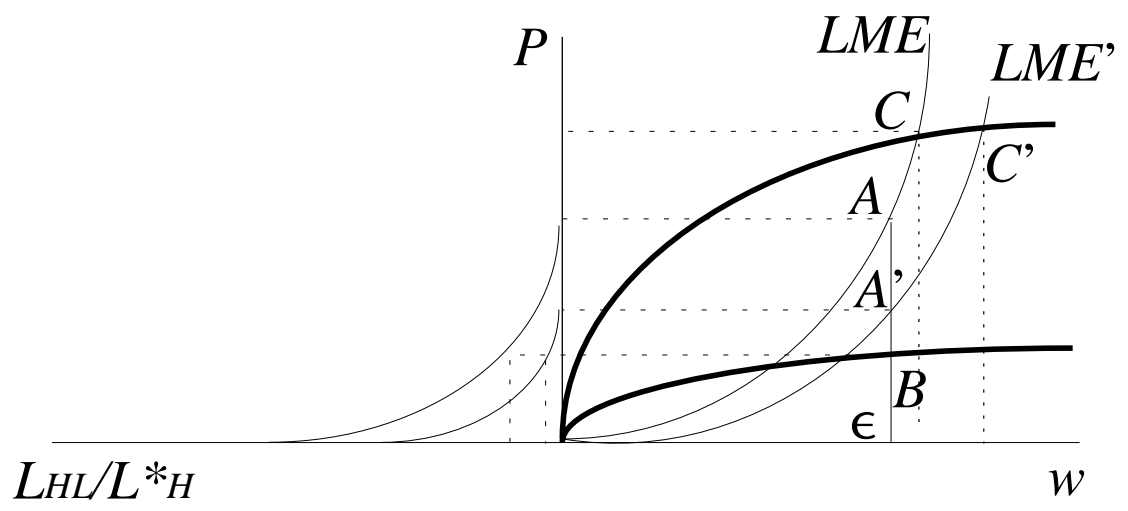

Figure 9: Comparative Statics, an increase in $n_{H}$

increase in $n_{H}$ causes a clockwise rotation in the $L M E_{H L=0}$-curve. ${ }^{11}$ This implies point $A$ moves down to $A^{\prime}$ and the intersection of $G M E$ and $L M E$ moves to the right and up to $C^{\prime}$. Under complete specialisation this implies higher relative prices, higher relative wages and divergence in unemployment rates. ${ }^{12}$ Under incomplete specialisation the rotation may lead to a regime shift. Then the previously mentioned price, wage and unemployment responses occur. When the shock is insufficient to induce a regime shift, the adjustment to equilibrium implies a reduction in $L_{H L} / L_{H}^{*}$ as can be verified in the upper left quadrant. The effects of an increase in $n_{L}$ do exactly the opposite.

Now we make a tentative link to empirical observation. Our model distinguishes two possible equilibria. Under incomplete specialisation we see positive skill mismatch that is reduced when product innovations are introduced. Relative wages remain stable, however, and thus relative unemployment does so to. This corresponds nicely with the findings on mainland Europe, where skill mismatch seems to be on the retreat and relative wages and unemployment rates do not show significant divergence. A possible explanation for the fact that Europe is in incomplete specialisation is the high minimum wages for low skilled labour and the policies to moderate high skilled wages. Although not analysed in this paper, such policies would push high skilled workers into the low skilled jobs. Our model does predict,

We assume for now the adjustment to equilibrium does not cause the relative price to fall below the critical relative price level for which no further high skilled employment can be attracted by the low sector producers at a relative wage $\epsilon$. 
however, that this stability of relative wages and unemployment will not last as the skill intensive sector expands.

Under complete specialisation our model predicts that increases in the range of skill intensive goods will cause wage divergence and divergence of unemployment rates. Mismatch is absent in this regime. This situation might apply to the United States, the United Kingdom and most countries in the British Commonwealth. In these countries mismatch is apparently not considered a big problem since hardly any attention is devoted to it in economic literature. Wage divergence and real wage decreases for low skilled workers, however, is al the more important and Nickell and Bell (1995) show biases in labour demand account for a large part of the asymmetry in unemployment in these countries counter to Krugman's analysis.

\section{Conclusions}

In this paper we have presented a model that generates two possible equilibria. Using the characteristics of these equilibria we can identify the regime of incomplete specialisation with mainland Europe whereas the Anglo-Saxon world seems to be completely specialised. This implies that both will respond differently to similar technological shocks.

A surge in the development of new products, that remains to be shown over the last decades but can certainly not be dismissed beforehand, can explain wage divergence and increasing asymmetries in unemployment in the Anglo-Saxon world whereas it also causes a decrease in skill mismatch in mainland Europe. We do acknowledge there are many more differences between and within these area's of the OECD and do not intend to explain all of the differences in labour market performance solely from this point of view. We do, however, contend that biased technical change can be a common cause without causing the same effects.

Furthermore our analysis sheds a different light on the policies implemented in the area's distinguished above. Relying on the so called chimney-effect to improve labour market perspectives for low skilled workers in Europe will eventually be self-defeating as complete specialisation is achieved. The undesirable side effects of such a regime are to be considered in formulating such policies. Policies of wage moderation do improve the situation for low skilled workers but imply welfare losses due to inefficient allocation of skills.

As to the US policy of promoting technical change and R\&D to create jobs for the unskilled, this may actually backfire. promoting $R \& D$ in general may increase the development and introduction of new products and cause an aggravation of the problem. Technology policy cannot, however, be evaluated without introducing an explicit R\&D sector into the model. we therefore put this at the top of our research agenda. For now we suffice by concluding the R\&D policy should be targeted in order to deal with the problem of asymmetric unemployment and wage divergence. 


\section{Annex: $\quad$ Alternative for the wage formation process}

The aim of this Annex is to present a wage formation process which is different from the process presented in the text above, but none-the-less yields a LME-curve with similar properties. This intends to illustrate the rather general nature of our analysis.

Assume that both high and low skilled wages are set by unions in a context of a right-tomanage model That is, wages are set such that the utility of the union is maximised given the implications for demand for labour- cf. equations (9') and (10).

The union that represents high skilled workers is assumed to desire the highest possible wage for it's members, but this wage must always exceed the low skilled wage by some factor $\gamma>1$ to compensate for the costs of acquiring the higher skills. Hence $w=w_{H} / w_{L}>\gamma$, should hold at all times. ${ }^{13}$ Moreover, high skilled employment is valued with an intensity $\xi$ relative to wages and we assume, some minimum acceptable level of employment, defined as a share $\delta$ of the "natural"employment level $\left(1-u^{*}\right) L_{H}{ }^{*}$. The union utility function is thus given by:

$$
U_{H}=w_{L}[w-\gamma]\left[L_{H H}-\delta[1-u *] L_{H}^{*}\right]^{\xi}
$$

The equilibrium demand for labour can be expressed as a function of relative wages by combining (9) and (10), which yields:

$$
L_{H H}=n_{H} l_{L} w^{-\frac{1}{1-\alpha \beta}}
$$

The union is assumed to take the average employment level in the other sector as given. Hence maximising utility with respect to relative wages subject to the demand for labour in equation (A2) yields: ${ }^{14}$

$$
L_{H H}=\frac{\delta[1-u *]}{1-\frac{\xi[1-\gamma / w]}{1-\alpha \beta}} L^{*}{ }_{H}
$$

13 For simplicity we assume that unemployment benefits are equal to the wage that would have been earned when working, minus benefits from leisure. Therefore being unemployed is not a threat in the bargaining process.

$$
w=\gamma \xi / \xi-[1-\alpha \beta]\left[1-\delta \frac{1-u^{*}}{1-u_{H H}}\right]
$$

which is very similar to (14). 
Preferences for the union representing the low skilled workers similarly express a desire for a highest possible wage, which must exceed their outside option, the unemployment benefit, $w_{u}$, by at least a factor $\gamma$ to compensate them for the leisure lost. ${ }^{15}$ Hence $w_{L^{-}} \gamma w_{u}>0$ at all times. Assuming unemployment benefits are a constant fraction $\zeta$ of low skilled wages, substituing for unemployment benefits and multiplying and dividing by the high skilled wage yields the excess of low skilled wages over their minimum acceptable wage as $w_{H}(1-\gamma \zeta) w^{-1}$. Like in the case of the union for high skilled labour we assume the union for low skilled labour also cares for employment. ${ }^{16}$ Moreover we assume for simplicity employment enters the union utility function in the same way as for the high skilled workers union:

$$
U_{L}=w_{H}[1-\gamma \zeta] w^{-1}\left[L_{L}-\delta[1-u *] L_{L}^{*}\right]^{\xi}
$$

Again we find the equilibrium demand for labour from combining (9') and (10):

$$
L_{L}=n_{L} l_{H H^{1}} w^{\frac{1}{1-\alpha \beta}}
$$

Since the low skilled union takes the level of high skilled wages and average high skilled employment as exogenous, maximising the utility function with respect to relative wages given labour demand yields:

$$
L_{L}=\frac{\delta[1-u *]}{1-\frac{\xi}{1-\alpha \beta}} L^{*}{ }_{L}
$$

Finally we assume that in equilibrium $L_{L e}=L_{L}+\epsilon L_{H L}$ holds, hence employers in the low skilled sector are assumed to be indifferent between high or low skilled labour, measured in efficiency units. Combining equations (A3) and (A6) yields the relative aggregate supply of labour:

$$
\frac{L_{H H}}{L_{L^{e}}}=\frac{\frac{\delta[1-u *]}{1-\alpha \beta-\xi[1-\gamma / w]} L_{H}^{*}}{\frac{\delta[1-u *]}{1-\alpha \beta-\xi} L^{*}{ }_{L}+\epsilon[1-\alpha \beta] L_{H L}}
$$

Taking the parameters $u^{*}, \gamma$ and $\psi$ for both bargaining processes is just for convenience and does not alter the qualitative results. jobs. 
Confronting this expression with the aggregate version of (10):

$$
\frac{L_{H H}}{L_{L^{e}}}=\frac{n_{H}}{n_{L}}\left[\frac{w}{P}\right] \frac{1}{\beta-1}
$$

yields the $L M E$-curve:

$$
P=w\left[\frac{n_{L}}{n_{H}}\right]^{1-\beta}\left[\frac{\frac{\delta[1-u *]}{1-\alpha \beta-\xi[1-\gamma / w]} L_{H}^{*}}{\frac{\delta[1-u *]}{1-\alpha \beta-\xi} L^{*}{ }_{L}+\epsilon[1-\alpha \beta] L_{H L}}\right]^{1-\beta}
$$

It can be shown that $L M E$-curve essentially has the same properties as the $L M E$-curve in (19). Both the first and second derivative with respect to $w$ are positive under our parameter restrictions, implying the $L M E$-curve is upward sloping and convex in $P, w$-space. The analysis then can be pursued along the lines after equation (19) in the text. 


\section{References}

Agenor P.R. and J. Aizenman (1996), 'Wage Dispersion and Technical Progress', in: NBER Working Papers Series, No. 5417

CBS (1995), Enquete Beroepsbevolking 1995, The Hague, the Netherlands

Berman, E., J. Bound and Z. Grilliches (1994), Changes in the Demand for Skilled Labor in US Manufacturing; Evidence from the Annual Survey of Manufactures', in: Quarterly Journal of Economics, Vol. CIX, No. 2, 367-397

Binswanger, H. (1974a),'A Microeconomic Approach to Induced Innovation', in: The Economic Journal, 84, 940-957

Binswanger, H. (1974b),'The Measurement of Biased Technical Change with many Factors of Production', in: American Economic Review, 64, No. 5, 964-976

Brauer, D. and S. Hickok (1995),'Explaining the Growing Inequality in Wages across Skill Levels', in: Economic Policy Review, Federal Reserve Bank of New York, 1 (January), 61-72

Burtless, G (1994),'International Trade and the Rise in Earnings Inequality', Journal of Economic Perspectives, 33 (June), 800-816

Draper, N. and T. Manders (1997), 'Structural Changes in the Demand for Labour, in: De Economist, 145 (4), 521-546

Feenstra, R. and G. Hanson (1997), 'Productivity Measurement and the Impact of Trade and Technology on Wages: Estimates for the U.S., 19972-1990', in: NBER Working Paper Series, No. 6052

Groot, W. and H. Maassen van den Brink (1996), 'Overscholing en Verdringing op de Arbeidsmarkt', in: Economisch Statistiche Berichten, 74 (7), 74-77

Halaby, C. (1994), 'Overeducation and Skill Mismatch', in: Sociology of Education, 67, 47-59

Howell, D. (1995),'Collapsing Wages and Rising Inequality: Has Computerisation Shifted the Demand for Skills?', Challenge, 38 (1), 27-35

Jackman, R. (1995), Unemployment and Wage Inequality in OECD Countries, London School of Economics, Oxford University Press

Kennedy, P. (1964), 'Induced Bias in Innovation and the Theory of Distribution', in: The Economic Journal, 74, no. 295, 541-547

Koopmans , M. and C. Teulings (1987),'Verdringing op de Arbeidsmarkt', in: Economisch Statistische Berichten, 72, 592-595 
Krugman, P. (1979), 'A Model of Innovation, Technology Transfer and the World Distribution of Income', in: Journal of Political Economy, 87 (2), 253-265

Krugman, P. (1995), ‘Technology, Trade and Factor Prices', in: NBER Working Paper Series, No. 5355

Lawrence, R. Z. and M. J. Slaughter (1993), 'International Trade and American Wages in the 1980s', in: Brookings Papers in Economic Activity, 2 (April), 161-210

Layard, R. and S. J. Nickell (1992), Unemployment in the OECD Countries, London School of Economics, Oxford University Press

Leamer, E. (1994), 'Trade, Wages and Revolving Doors Ideas', in: NBER Working Papers Series, No. 4716

Leamer, E. (1995),'A Trade Economist's View of US Wages and Globalization', in: Collins, ed. (1995), Imports, Exports and the American Worker, Washington: Brookings

Muysken, J. and B. Ter Weel (1998), 'Overeducation and Crowding Out of Low-Skilled Workers', MERIT Research Memorandum 98-023, Maastricht University, Maastricht

Nickell, S. and B. Bell (1995),'The Collapse in Demand for the Unskilled and Unemployment across the OECD', in: Oxford Review of Economic Policy, 11 (1), 40-62

OECD (1994), Jobs Study, Evidence and Explanations, Part I; Labour Market Trends and Underlying Forces of Change, OECD, Paris

Phelps and Dandrakis (1966),'A Model of Induced Invention, Growth and Distribution', in: the Economic Journal, 76, no. 304, 823-840

Salter, W. (1960), Productivity and Technical Change, Cambridge

Teulings and Hartog, (1998), Corporatism or competition?, Cambridge University Press, UK

Zon van A., H. Meijers and J. Muysken (1998), 'Sweeping the Chimney before kindling the Fire as a Workable option for Employment Policy', in: MERIT Research Memorandum, 2/98016, MERIT, Maastricht 